\title{
Some ethical issues in dementia research
}

\author{
B Mahendra St Bartholomew's Hospital, London
}

\section{Author's abstract}

The ethical problems associated with dementia have been thrown into focus by the ageing population. The elderly form a disadvantaged group in society and the author wonders if it is morally justified to pursue research into ways of arresting pathology without concomitant attention being paid to the quality of life of the surviving elderly. Precise diagnosis of dementia requires invasive, and potentially injurious, brain biopsy. Recent thinking has pointed to some of the advantages of biopsy. The question of consent in a patient with impaired mental function has to be borne in mind. As for the special ethical problems associated with Huntington's chorea, it is argued there is no justification for withholding information from, or for authoritarian direction of, patients and 'at risk' relatives but the importance of full discussion before undertaking predictive procedures is stressed.

The future extent of the problems to be posed by old age and senile dementia is not in dispute. Dementia refers to an acquired condition in which memory, intellect and personality are adversely affected, often but not necessarily in a progressive and irreversible way. Ninety per cent of cases of dementia occur in the senile population and about 10 per cent of the patients are pre-senile. The dividing line between senile and pre-senile groups is the age of 65 , a purely arbitrary distinction traceable, it is alleged, to Bismarck who decided that State old age pensions should be payable at that age. The causes of dementia are several, dementia merely being the common end-point of several pathological processes. Though senile dementia accounts for by far the most cases with over 700,000 patients in England and Wales, there are small but significant numbers of other kinds of demented patients - for instance about 5,000 sufferers with dementia due to Huntington's chorea - and many of these often raise special problems of their own.

About 80 per cent of cases of dementia are beyond the scope of any reasonable prospect of cure and most dementing illnesses, in particular those due to

\section{Key words}

Dementia; research; medical ethics; old age; investigation; brain disease; consent; Huntington's chorea.
Alzheimer's disease and multi-infarct vascular disease, tend to reduce life expectancy to a fraction of that to be $\overrightarrow{0}$ expected in the healthy of the same age.

In the 20 per cent or so of cases who present with a picture of dementia and expect to be treated, there is at $ᄋ$ least a possibility that pathology if not chronology may be reversed and the sick old patient returned to $?$ society as a healthy old person. Straightaway, we are faced with the question of whether or not it is $\vec{J}$ permissible to do research into dementia in the elderly. $\overrightarrow{0}$

Obvious though it may be, one has to emphasise that $\stackrel{\infty}{\oplus}$ research into dementia is quite distinct from research into ageing. The problems of the normal aged in the population have become well known, especially since their numbers have begun to change the demographic balance. The wider question it is legitimate to ask is whether it is justifiable to seek to transfer scarce resources in order to reverse sickness and prolong life by researching a group of patients who when they are freed of pathology may well, in contemporary society, expect in general to experience hardship and a certain measure of rejection by younger people.

If the elderly were invariably able to lead their lives with satisfaction and dignity in the absence of sickness, there would be no difficulty in urging that our energies be directed towards the pursuit of such knowledge and its application. But in a situation such as the one that obtains it might be felt that the traditional scientific belief in dispassionately pursuing any subject of interest may have to be tempered by the realisation that simply freeing people of pathology can raise other $\mathcal{N}$ ethical problems. As in numerous other clinical N situations the wider question of the quality of life to be N enjoyed by the patient, or his counterpart when $O$ rendered free of illness, must be taken into consideration. Also, though the milieu of the elderly might already be considered unpromising it is a sobering thought that when the fruits of current research come to be consumed, the expectation must be, at present, that the socio-economic circumstances of the elderly will have worsened and the quality of their existence become so much the grimmer.

It might be argued, therefore, that the researcher into dementia, before he becomes too carried away in 8 his enthusiasm for errant molecules in synapses, has a moral duty to engage the younger members of society 
and confront them with the fact that it is not enough to assuage their consciences by sanctioning research into one of the more serious illnesses in old age while continuing to choose to turn away from the larger issue of social provision for the elderly population.

Sound clinical research begins with precise diagnosis utilising all available investigatory tools. For the most part investigations on demented patients, including clinical assessment, psychometric evaluation, electroencephalograph (EEG) recordings, most blood-flow techniques and computerised tomography are noninvasive and are accepted without controversy. Unfortunately, in our present state of knowledge, the diagnosis of the most important cause of dementia, Alzheimer's disease, is possible only by cerebral biopsy and by subsequent histological and, to a lesser extent, histochemical study. Any invasion of the brain arouses profound suspicion. Though the procedure for brain biopsy has a small but definite risk of complication, the objection and opposition to the operation is not so much this risk but perhaps the emotional difficulty on the part of patients, relatives and doctors in accepting an assault on this last great bastion of human anatomy. In this respect the issues are similar to the problems associated with electroconvulsive therapy (ECT), though the latter is part of therapy, the former part of diagnosis. With ECT the possibility of aggravating underlying brain lesions and of producing memory impairment is also a small but definite risk to be weighed against the generally accepted efficacy of the procedure on severe, chronic and intractable cases of depressive illness. But the generally cautious and selective use of ECT these days has not damped very much the lively controversy that has surrounded this procedure, which has now been in use some fifty years and, again, the criticisms are not always based on real and calculable risks but on the grounds of 'assault' on the patient's mind and dignity by this largely empirical procedure.

When it comes to cerebral biopsy, can the real risks of the operation on a given patient justifiably be set against the real risks of failure to gain precise knowledge of groups of patients by not performing it? Undoubtedly at present a diagnosis of Alzheimer's disease is likely to be only of academic interest as far as the individual patient is concerned. However, there is much work going on into the illness. When and if potentially therapeutic agents become available there can be little doubt that a reversal of the symptoms of the illness will only be successful if treatment is carried out immediately after early diagnosis. Current interest is focused on memory difficulties with histochemical correlates which need to be detected and countered by replacement chemicals. When this form of chemical treatment might become fully established and available is uncertain; but if the experimental drugs are not used on trial patients with early symptoms - subject, of course, to the usual ethical considerations applicable to clinical trials - there probably will not be any prospect for development of this treatment. Similar considerations apply to other potential treatments. However, the later stages of dementia, involving intellectual deficits and personality disorganisation as well, are not at present thought to be reversible.

Further, some 20 per cent of demented patients are treatable by conventional management of the causes of their dementing state. It is possible to argue with some conviction in this context that a negative biopsy result (meaning that the cause of the dementia is not Alzheimer's disease) may add extra impetus to the further search for a treatable cause. We know that Alzheimer's disease is not only one of the commoner causes of dementia but also that it is one of those that is at present untreatable; on the other hand if a biopsy does not reveal Alzheimer's disease the chances that the cause is a less common but perhaps therapeutically more promising condition greatly improve. In these circumstances it might be thought that ethical pressures would be in the direction of performing an early biopsy. Moreover, as Torack (1) has discussed, a normal biopsy result may afford a more favourable prognosis than any pathological result, even when the dementia is of comparable severity. (This may seem confusing but dementia is a clinical evaluation; the biopsy refers to a technical procedure. It is possible to be demented with a known cause, unknown cause or even with normal 'pathology' on biopsy). If it is agreed that there is a moral duty to inform patients fully of the implications of their illness, it may be argued there is a strong case for low risk brain biopsy in the search for relevant information about that illness.

Before any procedure is undertaken there is an assumption of consent, implied or explicitly given, on the part of the patient. Consent implies a rational mind capable of understanding the issues and possessed of the judgement necessary to consent. Unfortunately, among the cardinal features of the dementia syndrome are loss of insight, intellect and judgement. The very features which are of clinical interest are those the patient is deprived of when called upon to give consent. Except in the earliest stages of the illness the patient probably has little capacity to give fully considered consent to any procedure which the investigator wishes to undertake and as the illness proceeds this capacity is reduced even further to the point that a rational decision cannot reasonably be expected from a patient. In the later, and terminal, stages of dementia consent regarding, say, autopsy and removal of the brain can only be obtained from relatives who will also be called upon to approve serial investigatory procedures, the first of which might have been done when the patient was in reasonably full possession of his or her faculties. In an effort to overcome this difficulty the idea has been mooted of the 'penultimate will' through which the patient, at the time of diagnosis (assuming it is relatively early in the course of the illness), makes his relatives the guardians of his body for the rest of his life. In theory this would seem an admirably simple solution. In practice it is most likely that intolerable pressure would be put on most relatives who might 
come to feel the term 'executors' had taken on an unintended meaning. In these circumstances the research worker will have to pay even greater heed to and be even more aware of the ethical implications of his activities and procedures if he is not to exploit a delicate situation.

These observations would apply in the main to the numerically large number of patients with senile dementia. An important pre-senile dementia, Huntington's chorea, presents special ethical difficulties for both clinician and research worker. Huntington's chorea is transmitted by an autosomal dominant genetic mechanism. Though the risk of disease varies with age the illness usually does not manifest until late adult life or middle age by which time a third affected generation from the initial patient might already have been conceived. There is no certain method yet of determining carrier status and any advice that might be given about the chance of developing the illness and hence the prospects for marriage and child-bearing can only inadequately be based on probabilities. Nonetheless, several tests have been used, and continue to be devised and used, to detect the carrier state and surveys in Britain, the USA and Australia $(2,3,4)$ have shown that 77 per cent to 84 per cent of subjects 'at risk' or related to Huntington's chorea patients wish to be informed, when an effective test becomes available, whether or not they are carriers. A question in these circumstances is whether in the absence of effective curative or palliative treatment of this seriously distressing illness the whole truth should be revealed to these subjects. Perry (5), a distinguished researcher into the condition, has said there is no justification for doing so. He says 'I suggest that pending development of an effective form of treatment, scientists who perform pre-clinical tests on persons at risk should ensure that the results of individual tests are not made available to those tested'. $\mathrm{He}$ also believes that there is little evidence that the incidence of Huntington's chorea has been reduced by any preventive measures taken so far. 'I wonder . . .', Perry says 'whether the non-directive approach towards genetic counselling that is now fashionable will ever succeed in reducing the incidence of Huntington's chorea .... I suggest that there is nothing inherently unethical in providing directive genetic counselling to persons at risk ... . Directive counselling need not be authoritarian'. This strikes one as being a slightly naive attitude. In being directive the physician is surely being authoritarian if only in the sense of exploiting his authority. There is also a lack of consistency in Perry's argument. On the one hand physicians are being urged to be conscious of their fallibility and helplessness and conceal the whole truth from subjects and yet, on the other, they are being advised to exert their authority to order the lives of healthy people in case the latter turn out to be affected and pass on the delinquent gene.
It seems extremely unlikely, in the light of the

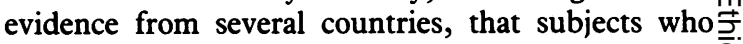
submit themselves to tests will agree to go away emptyhanded when the results become available to the investigators. Whether there is ethical justification under any circumstances for deliberately depriving $\bar{C}$ subjects of knowledge that has been obtained by doing tests on their bodies is questionable. And whether an? authoritarian - that is what it will be in practice - ban尺 on the activities of individuals on grounds of ${ }_{\tilde{W}}^{\circ}$ probability is likely to be ethically justified (or effective) is moot.

One approach is to discuss the issues with persons 'at $\vec{\omega}$ risk' before the tests are undertaken. The nature of $\mathrm{O}$ Huntington's chorea makes most relatives perfectly aware at first hand of the consequences of having the disease and if the subject opts out of a situation which. might bring him face to face with a fateful future it is $\vec{\sim}$ likely to be a well-considered decision.

The full extent of the ethical problems surrounding $\mathrm{P}$ dementia may only be realised when senile dementia becomes, as it threatens to in the remaining years of this century, one of the main public health problems. On the other hand and ironically, the sheer extent of the problem may well ease some of the ethical $\infty_{\infty}^{\infty}$ difficulties with which we are preoccupied today. The ${ }^{+}$ morality and ethics of birth control and abortion once preoccupied people to an inordinate degree and led tos repressive attitudes on the part of those in authority. The realisation that strictures on birth control and abortion were incompatible both with increasing personal freedom and with the need for population $\overrightarrow{\vec{O}}$ limitation helped change attitudes. It is possible that 3 realistic appraisal of a situation likely to arise in the fairly near future could exert a similar influence on ouro. consideration of the ethical issues in dementia.

\section{Acknowledgement}

The author is supported by the Wellcome Trust.

\section{References}

(1) Torack R M. Adult dementia: history, biopsy, pathology. $N$ Neurosurgery 1979; 4, 5: 434-442.

(2) Barette J, Marsden C D. Attitudes of families to some aspects of Huntington's chorea. Psychological medicinew 1979; 9: 327-336.

(3) Stern R, Eldridge R. Attitudes of patients and theiro relatives to Huntington's disease. Fournal of medical genetics 1975 ; 12: 217-223.

(4) Teltcher B, Polgar S. Objective knowledge about Huntington's disease and attitudes towards predictive $\overline{-}$ testing of persons at risk. Fournal of medical genetics $1981 ; \overline{\mathbb{D}}$ 18: 31-39.

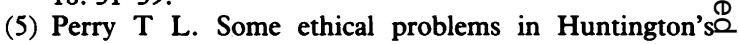
chorea. Canadian Medical Association journal 1981; 125: 1098-1100. 